\title{
AD WATCH
}

\section{The vestiges of cigarette advertising in Norway}
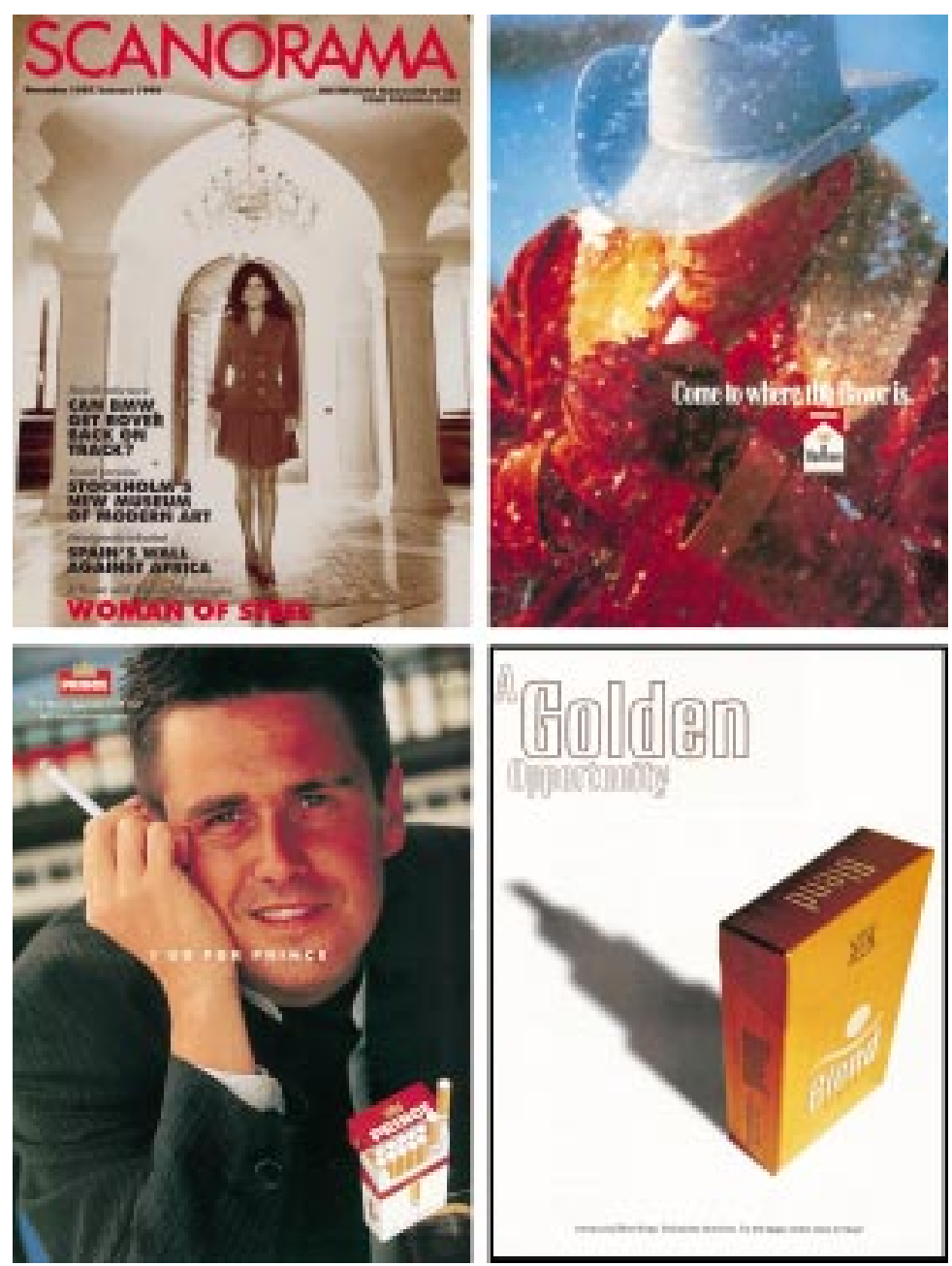

Figures 1-4 Three cigarette ads, without health warnings, appeared in the December 1997/fanuary 1998 issue of Scanorama, the inflight magazine of SAS.
On a recent one-day trip to Oslo, Norway, I was pleased to be in a country with no cigarette advertising-well, almost none. Marlboro duty-free shopping bags were ubiquitous in the Oslo airport, as they are in most airports around the world. In addition, three full-page cigarette ads (without health warnings!) were in Scanorama, the inflight magazine of Scandanavian Airlines System (SAS) (figures 1-4). Scanorama is published by Media Partner SMP AB, a company based in Stockholm, and the magazine notes that its editor-in-chief is "responsible under Swedish press law".

The cigarette advertising in the airplane and airport was somewhat counterbalanced by ads for Nicorette ("Enjoy life without cigarettes") on the back of SAS boarding passes (figure 5) and on the airline's ticket envelopes.

RONALD M DAVIS

Editor

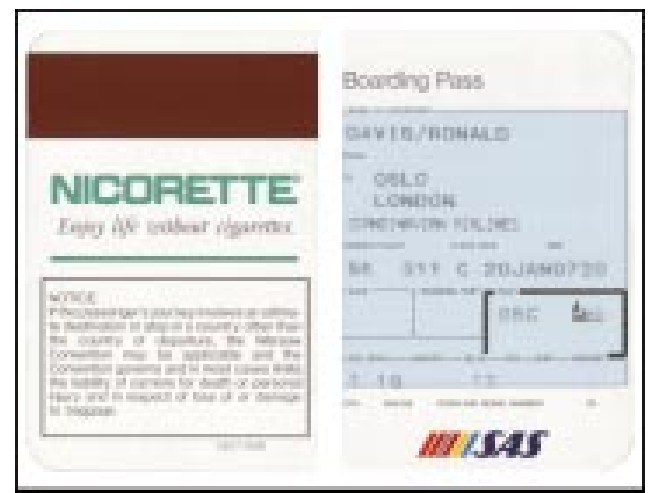

Figure 5 An advertisement for Nicorette on the back of an $S A S$ boarding pass. 